Revista Destaques Acadêmicos, Lajeado, v. 12, n. 1, 2020. ISSN 2176-3070

DOI: http://dx.doi.org/10.22410/issn.2176-3070.v12i1a2020.2484

http://www.univates.br/revistas

\title{
TERCEIRIZAÇÃO DA MÃO DE OBRA: UMA ANÁLISE SOB A ÓTICA DO EMPREGADO E DO EMPREGADOR
}

\author{
Jhonas Roberto Piovezana dos Santos ${ }^{1}$, Diones Kleinibing Bugalho², \\ Francieli Morlin ${ }^{3}$
}

\begin{abstract}
Resumo: O objetivo deste estud o foi avaliar as vantagens e desvantagens da terceirização da mão de obra, sob a ótica do empregado e empregador levando em consideração os aspectos econômicos, legais e sociais envolvidos na relação trabalhista de duas maneiras de contrato de trabalho, via Consolidação das Leis Trabalhistas (CLT) e via contrato de terceirização por Micro Empreendedor Individual (MEI). Trata-se de um estudo de descritivo, realizado por meio de estudo de caso, com abordagem qualitativa e quantitativa. A pesquisa foi realizada no setor do açougue de um supermercado localizado na cidade de Pato Branco - PR. A escolha desta população, justifica-se pela motivação do proprietário do estabelecimento em iniciar o processo de terceirização de setores específicos do supermercado, iniciando pelos setores que possuem o maior custo de folha de pagamento. Para realização do estudo comparativo, foram coletados os dados da folha de pagamento dos dois funcionários deste setor. Os achados revelam que para os dois funcionários a opção pela terceirização não é vantajosa, enquanto que para o empregador a terceirização torna-se extremamente vantajosa. No caso do Empregado/Contratado 1, é possível observar uma redução de 35,32\% nos custos de mão de obra, enquanto que o Empregado/Contratado 2 responde por uma redução de $27,88 \%$ nos custos com mão de obra.
\end{abstract}

Palavras-chave: Terceirização, Consolidação das Leis Trabalhistas, CLT, Microempreendedor Individual, MEI.

1 Bacharel em Ciências Contábeis - Faculdade Mater Dei.

2 Mestrando em Ciências Contábeis e Administração (PPGCCA) - UNOCHAPECÓ.

3 Mestranda em Contabilidade (PPGC) - UFSC. 


\section{INTRODUÇÃO}

Dado ao atual panorama econômico brasileiro, o crescimento e a prosperidade das empresas dependem da capacidade destas, de se resguardar, economizar e otimizar seus recursos. Desse modo, se torna essencial buscar formas de melhorar suas oportunidades de crescer e se manter no mercado (PONTES, 2011). O cenário recente de crise econômica aliado a globalização forçou com que a legislação brasileira fosse alterada no sentido de criar meios de flexibilização do trabalho, objetivando o aumento de empregos, o aumento da capacidade de empresas de se manterem ativas, como uma possível solução para auxiliar no crescimento econômico do país (GABAS, 2016).

Pesquisas recentes revelam que a terceirização pode proporcionar às empresas vários benefícios econômicos, tecnológicos e estratégicos (ALTIN et al., 2018; ESPINO-RODRIGUES e RAMÍRES-FIERRO, 2018). Neste sentido, a terceirização pode beneficiar a empresa, proporcionando um menor custo de produção em comparação com a produção interna, devido à especialidade dos prestadores de serviços externos e suas economias de escala (GILLEY et al., 2004). Por outro lado, a terceirização é vista como uma ferramenta estratégica para obter vantagem competitiva devido ao foco nas atividades principais, ao terceirizar as atividades específicas a especialistas externos; assim, a empresa pode se sair melhor com atividades essenciais e não essenciais (ESPINORODRÍGUES e RAMÍRES-FIERRO, 2018).

Além disso, em um ambiente dinâmico e competitivo, a terceirização permitiu a adaptação a novas tecnologias ou serviços inovadores (ALTIN et al., 2018) No entanto, a literatura é difusa no sentido de que alguns estudos apontam influência positiva da terceirização no desempenho organizacional (ELMUTI, 2003), enquanto que outros não encontraram impacto significativo (CHATZOGLOU e SARAGIANNIDIS, 2009), ou mesmo impacto negativo (ESPINO-RODRÍGUES e GIL-PADILHA, 2009). Eventualmente, Baytok et al. (2013) classificaram os benefícios da terceirização em quatro categorias. Suas descobertas revelaram que os benefícios mais importantes da terceirização estão dentro de um aumento no serviço e na qualidade, benefícios administrativos, benefícios financeiros e benefícios organizacionais, respectivamente. Além disso, Espino-Rodrígues et al. (2012) indicaram que os benefícios e riscos percebidos da terceirização podem influenciar substancialmente a estratégia de terceirização de cada organização.

Com base nessa discussão, o presente estudo possui a seguinte problemática: Quais as vantagens e desvantagens da terceirização da mão de obra, sob a ótica do empregado e empregador. Nesse sentido, cabe ressaltar que a terceirização da mão de obra de qualquer atividade da empresa, seja ela de meio ou de fim, foi uma das grandes mudanças trazidas pela Lei 13.467/2017, que trouxe consigo a diminuição dos valores despendidos com encargos trabalhistas, aliviando o orçamento das empresas sem deixar de prestar um serviço de qualidade. 
Para responder o questionamento da pesquisa, traçou-se o objetivo de avaliar as vantagens e desvantagens da terceirização da mão de obra, sob a ótica do empregado e empregador levando em consideração os aspectos econômicos, legais e sociais envolvidos na relação trabalhista de duas maneiras de contrato de trabalho, via Consolidação das Leis Trabalhistas (CLT) e via contrato de terceirização por Micro Empreendedor Individual (MEI).

A realização desta pesquisa justifica-se pela relevância e novidade do assunto no Brasil, pois, com a mudança na legislação, a terceirização passa a ser uma importante ferramenta possível tanto para empregadores e empregados.

\section{REFERENCIAL TEÓRICO}

Faz-se necessário neste estudo apresentar a fundamentação teórica, com pesquisas realizadas sobre o tema que possam contribuir com a compreensão e sustentação da pesquisa. Essa seção aborda o custo da legislação trabalhista no país, seguida pela terceirização da mão de obra, e por fim a evolução da terceirização no Brasil.

\subsection{O Custo da Legislação Trabalhista no Brasil}

O direito do trabalho no Brasil possui desde os seus primórdios características a proteção do proletariado, sendo entendido como a parte mais fraca na relação de emprego, através da intervenção estatal na criação de leis garantidoras dos direitos básicos dos trabalhadores (NASCIMENTO, 2014). A legislação trabalhista Brasileira tem por primazia a proteção dos trabalhadores, que não podem de outra forma defender-se do poderio econômico dos empregadores, e foi através da criação de leis que determinam valores, acréscimos e institutos que o Estado encontrou escopo para proteger o proletariado. São direitos de todos os trabalhadores aqueles elencados na Constituição Federal em seu artigo $7^{\circ}$ e seus 34 incisos (BRASIL, 1988).

De acordo com o Instituto de Pesquisa Econômica Aplicada - IPEA, em 2015 a depender da duração do vínculo empregatício, os gastos da empresa com um funcionário podem chegar a quase o triplo do salário mensal registrado em carteira. Para Gabas (2016), esse cenário deixa de ser atrativo para quem deseja empreender, afastando investimentos e prejudicando o crescimento das empresas.

Os principais componentes do custo do trabalho para as empresas, agrupados em quatro classificações que são sugeridas pela Organização para a Cooperação e Desenvolvimento Econômico (OCDE), adaptadas ao caso brasileiro: a. Salário base: salário mensal líquido recebido pelo trabalhador. B. Recebimento: Salário base acrescido do pagamento de horas-extras, bônus, adicionais, participação nos lucros e resultados (PLR), $13^{\circ}$ salário, adicional de férias e vales alimentação e transporte. C. Compensação dos empregados: É o recebimento acrescido das contribuições ao FGTS, ao INSS e a planos de 
previdência privados, assistência médica ou seguro saúde, auxílio farmácia, auxílio creche e demais benefícios, além dos custos rescisórios (multa do FGTS e aviso prévio). D. Custo Total do Trabalho: É a compensação do trabalho acrescida dos custos treinamento e capacitação, outros custos do trabalho ainda não classificados (custos para transportar trabalhadores, vestuário de trabalho, recrutamento) e impostos/contribuições (IRPF, salário educação, INCRA e sistema S). Sendo as classificações são cumulativas (SOUZA; At al, 2012).

O custo da legislação trabalhista pode ser, portanto, definida como a diferença entre o custo total do empregado para a empresa e o valor do contrato de trabalho percebido pelo empregado, devendo ainda ser incluído neste cálculo o valor da Justiça do Trabalho, não o do descumprimento da lei por parte do empregador visto que este assumiu o risco, mas sim o valor oculto que advém da instabilidade e da falta de segurança jurídica, quando há mudança na interpretação de certo dispositivo e a criação de jurisprudências que divergem da interpretação fria da letra da lei (SOUZA; At al, 2012).

\subsection{Terceirização da Mão de Obra}

A terceirização pode ser conceituada como a transferência das atividades laborais consideradas secundaria de uma pessoa jurídica (empresa tomadora) para outra pessoa jurídica (empresa prestadora de serviço) que tenha especialização na área especifica visando à concentração nas atividades reputadas como mais significativas e primordiais possibilitando assim o incremento da atividade da empresa, criando espaço para a busca da melhor competitividade gerada pela redução de custos e especialização (SERAU JUNIOR, 2018).

O termo terceirização é utilizado na linguagem corrente para designar uma técnica de organização empresarial, que vem tendo emprego cada vez mais comum. Trata-se de um neologismo que designa a divisão do processo produtivo entre a empresa que promove e outras que fornecem parte dos componentes ou dos serviços necessários à obtenção do produto final e à sua colocação no mercado (VIDAL NETO, 1996).

Segundo Soares Junior (2013) a terceirização constitui uma das mais importantes técnicas a ser utilizada nos processos de produção, especialmente do ponto de vista de uma possibilidade quanto à aplicação e implementação objetivando o aumento e principalmente a qualidade da produção. A terceirização enquanto técnica empresarial tem muito para ser desenvolvida e aperfeiçoada, seu campo de atuação é quase limitado, nesse sentido a Terceirização é a contratação de terceiros, por uma empresa, para prática de atividades geral, visando a racionalização de custos, a economia e a desburocratização administrativa (SERAU JUNIOR, 2018).

A terceirização caracteriza-se pela formação de uma relação trilateral na contratação do trabalho para a produção capitalista, de modo que o obreiro 
terá seu vínculo jurídico-trabalhista com uma determinada empresa e prestara serviços a outra. Portanto, não assumindo a posição de empregadora, se livrando assim dos encargos trabalhistas que seriam inerentes a tal condição. Uma dissociação entre a relação econômica de trabalho e a relação trabalhista que lhe seria correspondente. (DELGADO, 2004).

Há ainda a problemática envolvendo a relação que se dará entre os empregados e o tomador de serviços no ambiente de trabalho. Conforme preconizado na Sumula n 331 do Tribunal Superior do Trabalho, a presença da subordinação direta e da pessoalidade na relação entre tomador e empregado tornara ilícita a terceirização, reconhecendo o vínculo de empregado entra suas partes (SERAU JUNIOR, 2018).

Assim, visando evitar a configuração da subordinação direta, e consequentemente do vínculo empregatício, as empresas tomadoras dispensam aos empregados terceirizados um tratamento diferente daquele direcionado aos outros empregados, isso gera um ambiente de trabalho hostil para os terceirizados, violando o princípio da isonomia e dificultando a aproximação entre os dois grupos de empregados, o que prejudica o espirito de coletividade entre os trabalhadores (FREDIANI, 2011).

\subsection{Evolução da Terceirização Brasil}

Em uma perspectiva de flexibilização da legislação trabalhista vinculada à política neoliberal de redução de custos relativos à mão de obra com a finalidade de aumento dos lucros, o Brasil incorporou a terceirização em seu aparato normativo. Os primeiros delineamentos da legislação brasileira sobre a terceirização em âmbito privado nascem na década de 60 , tratando da possibilidade de contratação para prestação de serviços em relação à segurança bancaria (CASTRO, 2018).

Com a criação do contrato de trabalho temporário, disciplinado pela Lei $\mathrm{n}^{\circ}$ 6.019/1974, passam a existir possibilidades mais amplas de permissão de terceirização, pois esse tipo de contratação deve ocorrer por meio de empresa prestadora de serviços que tenha como finalidade disponibilizar mão de obra temporária, assim, regulamentar trabalho temporário também pode ser entendido como regulamentar terceirização de mão de obra. Posteriormente, em 1983, foi promulgada a Lei $n^{\circ} 7.102$, afim de regular a segurança para estabelecimentos financeiros, instituindo normas para constituição e funcionamento das empresas particulares terceirizadas que exploram serviços de vigilância e de transporte de valores (DELGADO, 2004).

Em 31 de março de 2017 foi sancionada a Lei $n^{\circ}$ 13.429, que dispõe acerca da nova regulamentação do trabalho temporário e do trabalho urbano terceirizado. Até então, havia escassa legislação especifica quanto à terceirização propriamente, sendo tida como base da regulamentação jurisprudência a sumula $\mathrm{n}^{\mathrm{o}} 331$ do Tribunal Superior do Trabalho. A nova lei acarretara 
diversos retrocessos para os trabalhadores, tendo em vista que amplia as possibilidades de terceirização, uma das faces da precarização do trabalho. A principal modificação ocorrida da nova regulamentação da terceirização é a possibilidade de terceirizar atividades-fim executadas pela empresa tomadora de serviço (CASTRO, 2018).

A reforma trabalhista prevê ainda na mesma linha de raciocínio, que o empregado que for demitido não poderá ser contratado por empresa prestadora de serviços e atuar como funcionário terceirizado da sua antiga empresa empregadora pelo prazo de 18 meses, a conta da sua demissão, isso impede que a empresa repasse sua equipe de trabalhadores para uma terceirizada (SERAU JUNIOR, 2018).

Segundo a lei, o trabalhador terceirizado deve ter igualdade de acesso as instalações da empresa em que trabalham os funcionários da empresa contratante, o que significa direito as mesmas condições de alimentação, quando realizada no refeitório da empresa em que trabalham, sanitários, ambulatórios, além dos serviços de transporte e dos equipamentos de segurança. Plano de saúde ou vale alimentação não se aplicam, pois decorrem da contratação com cada empregador (SERAU JUNIOR, 2018).

\section{PROCEDIMENTOS METODOLÓGICOS}

Trata-se de um estudo de descritivo, realizado por meio de estudo de caso, com abordagem qualitativa e quantitativa. A pesquisa foi realizada no setor do açougue de um supermercado localizado na cidade de Pato Branco PR. A escolha desta população, justifica-se pela motivação do proprietário do estabelecimento em iniciar o processo de terceirização de setores específicos do supermercado, iniciando pelos setores que possuem o maior custo de folha de pagamento.

Para realização da pesquisa, foram utilizadas as folhas de pagamento dos três empregados que atuam no setor do açougue deste supermercado, cabe ressaltar que todos são contratados mediante contrato CLT, com todos os custos trabalhistas envolvendo esse tipo de contrato conforme determina a legislação. Para realizar o comparativo, o estudo faz projeções destes custos num cenário em que fossem contratados mediante ao contrato terceirizado por meio de um MEI. Dessa forma é possível avaliar as vantagens e desvantagens para os contratados.

Os dados utilizados para o comparativo, são as folhas de pagamentos do ano todo. Dessa forma é possível comparar todos os custos envolvidos no contrato, de trabalho atual considerados sazonais, como férias, gratificação natalina, horas extras, etc. Por fim, os resultados dessa comparação foram apresentados aos empregados para que avaliem essa possibilidade com o intuito de obter a percepção destes em relação a terceirização, apresentando as vantagens e desvantagens deste modelo de contrato de trabalho. Nesse 
comparativo, foram apresentadas simulações envolvendo o salário atual dos empregados, levando em consideração para o contrato de terceirização o mesmo valor.

\section{RESULTADOS}

Inicialmente, a pesquisa apresentará os valores recebidos pelos empregados, com o devido salário mensal de todos os empregados, com o salário bruto, desconto do Instituto Nacional da Seguridade Social - INSS, desconto do Imposto de Renda Retido na Fonte - IRRF e o depósito do Fundo de Garantia - FGTS. Além disso, o supermercado é enquadrado pelo Lucro Real, e desse modo, é obrigado a fazer o depósito de $20 \%$ do INSS patronal destinado à previdência social. A Tabela 1, apresenta os dados referentes ao auxiliar de açougue.

Tabela 1 - Custos Empregado 1 por Contrato CLT

\begin{tabular}{c|c|c|c|c|c|c}
\hline \multicolumn{7}{c}{ Empregado 1 - Auxiliar de Açougue - Contrato CLT } \\
\hline Mês & Sal. Bruto & $\begin{array}{c}\text { INSS } \\
\text { Emp. }\end{array}$ & IRRF & $\begin{array}{c}\text { Sal. } \\
\text { Líquido }\end{array}$ & FGTS & INSS Pat. \\
\hline jan/19 & $\mathrm{R} \$ 1.867,16$ & $\mathrm{R} \$ 168,04$ & - & $\mathrm{R} \$ 1.699,12$ & $\mathrm{R} \$ 149,37$ & $\mathrm{R} \$ 373,43$ \\
\hline fev/19 & $\mathrm{R} \$ 1.842,15$ & $\mathrm{R} \$ 165,79$ & - & $\mathrm{R} \$ 1.676,36$ & $\mathrm{R} \$ 147,37$ & $\mathrm{R} \$ 368,43$ \\
\hline mar/19 & $\mathrm{R} \$ 1.853,53$ & $\mathrm{R} \$ 166,82$ & - & $\mathrm{R} \$ 1.686,71$ & $\mathrm{R} \$ 148,28$ & $\mathrm{R} \$ 370,71$ \\
\hline abr/19 & $\mathrm{R} \$ 1.829,47$ & $\mathrm{R} \$ 164,65$ & - & $\mathrm{R} \$ 1.664,82$ & $\mathrm{R} \$ 146,36$ & $\mathrm{R} \$ 365,89$ \\
\hline mai/19 & $\mathrm{R} \$ 1.862,11$ & $\mathrm{R} \$ 167,59$ & - & $\mathrm{R} \$ 1.694,52$ & $\mathrm{R} \$ 148,97$ & $\mathrm{R} \$ 372,42$ \\
\hline jun/19 & - & - & - & - & - & - \\
\hline jul/19 & $\mathrm{R} \$ 1.935,25$ & $\mathrm{R} \$ 174,17$ & - & $\mathrm{R} \$ 1.761,08$ & $\mathrm{R} \$ 154,82$ & $\mathrm{R} \$ 387,05$ \\
\hline ago/19 & $\mathrm{R} \$ 2.142,34$ & $\mathrm{R} \$ 192,81$ & - & $\mathrm{R} \$ 1.949,53$ & $\mathrm{R} \$ 171,39$ & $\mathrm{R} \$ 428,47$ \\
\hline set/19 & $\mathrm{R} \$ 1.795,53$ & $\mathrm{R} \$ 161,60$ & - & $\mathrm{R} \$ 1.633,93$ & $\mathrm{R} \$ 143,64$ & $\mathrm{R} \$ 359,11$ \\
\hline out/19 & $\mathrm{R} \$ 1.847,75$ & $\mathrm{R} \$ 166,30$ & - & $\mathrm{R} \$ 1.681,45$ & $\mathrm{R} \$ 147,82$ & $\mathrm{R} \$ 369,55$ \\
\hline nov/19 & $\mathrm{R} \$ 1.864,78$ & $\mathrm{R} \$ 167,83$ & - & $\mathrm{R} \$ 1.696,95$ & $\mathrm{R} \$ 149,18$ & $\mathrm{R} \$ 372,96$ \\
\hline dez/19 & $\mathrm{R} \$ 1.917,22$ & $\mathrm{R} \$ 172,55$ & - & $\mathrm{R} \$ 1.744,67$ & $\mathrm{R} \$ 153,38$ & $\mathrm{R} \$ 383,44$ \\
\hline $13^{\circ}$ Sal. & $\mathrm{R} \$ 1.887,03$ & $\mathrm{R} \$ 169,83$ & - & $\mathrm{R} \$ 1.717,20$ & $\mathrm{R} \$ 150,96$ & $\mathrm{R} \$ 377,41$ \\
\hline Férias & $\mathrm{R} \$ 2.426,67$ & $\mathrm{R} \$ 218,40$ & $\mathrm{R} \$ 22,82$ & $\mathrm{R} \$ 2.185,45$ & $\mathrm{R} \$ 194,13$ & $\mathrm{R} \$ 485,33$ \\
\hline Total & $\mathrm{R} \$ 25.070,99$ & $\mathrm{R} \$ 2.256,39$ & $\mathrm{R} \$ 22,82$ & $\mathrm{R} \$ 22.791,78$ & $\mathrm{R} \$ 2.005,68$ & $\mathrm{R} \$ 5.014,20$ \\
\hline
\end{tabular}

Fonte: Dados da pesquisa

A Tabela 1, tem por objetivo evidenciar o salário recebido pelo empregado durante o ano de 2019, bem como os custos desse empregado ao empregador. Ou seja, levando em consideração os depósitos de FGTS na conta vinculada ao empregado, bem como o INSS Patrimonial. É possível observar 
que durante o ano o empregado recebeu um montante líquido de $\mathrm{R} \$ 22.791,78$, esse valor é referente ao salário bruto, somado com a gratificação natalina, que também é conhecida como $13^{\circ}$ salário, juntamente com as férias, deduzindo o INSS de seu salário a uma alíquota de 9\%. É possível observar que durante o mês de junho de 2019 o empregado não recebeu salário, por ser o período que ficou de férias durante os 30 dias do mês. Além disso, o empregado recebeu em todos os meses valores referentes a hora extra, o que justifica o salário bruto variável em todos os meses.

Em relação ao custo para o empregador, o auxiliar de açougue apresentou um custo total durante o ano de 2019 de $\mathrm{R} \$ 32.090,87$ que corresponde a soma do salário bruto, juntamente com o FGTS e o INSS patronal, calculados a alíquotas de $8 \%$ e $20 \%$ respectivamente. A seguir, apresenta-se a Tabela 2 com os valores correspondentes ao empregado 2, o qual atua na função de açougueiro.

Tabela 2 - Custos Empregado 2 por Contrato CLT

\begin{tabular}{c|c|c|c|c|c|c}
\hline \multicolumn{7}{c}{ Empregado 2 - Açougueiro - Contrato CLT } \\
\hline Mês & Sal. Bruto & INSS & IRRF & Sal. Líquido & FGTS & INSS Pat. \\
\hline jan/19 & $\mathrm{R} \$ 3.375,96$ & $\mathrm{R} \$ 371,36$ & $\mathrm{R} \$ 95,89$ & $\mathrm{R} \$ 2.908,71$ & $\mathrm{R} \$ 270,08$ & $\mathrm{R} \$ 675,19$ \\
\hline fev/19 & $\mathrm{R} \$ 3.362,50$ & $\mathrm{R} \$ 369,88$ & $\mathrm{R} \$ 94,09$ & $\mathrm{R} \$ 2.898,53$ & $\mathrm{R} \$ 269,00$ & $\mathrm{R} \$ 672,50$ \\
\hline mar/19 & $\mathrm{R} \$ 3.339,79$ & $\mathrm{R} \$ 367,38$ & $\mathrm{R} \$ 91,06$ & $\mathrm{R} \$ 2.881,35$ & $\mathrm{R} \$ 267,18$ & $\mathrm{R} \$ 667,96$ \\
\hline abr/19 & $\mathrm{R} \$ 3.380,00$ & $\mathrm{R} \$ 371,80$ & $\mathrm{R} \$ 96,43$ & $\mathrm{R} \$ 2.911,77$ & $\mathrm{R} \$ 270,40$ & $\mathrm{R} \$ 676,00$ \\
\hline mai/19 & $\mathrm{R} \$ 3.394,88$ & $\mathrm{R} \$ 373,44$ & $\mathrm{R} \$ 98,42$ & $\mathrm{R} \$ 2.923,02$ & $\mathrm{R} \$ 271,59$ & $\mathrm{R} \$ 678,98$ \\
\hline jun/19 & $\mathrm{R} \$ 3.397,55$ & $\mathrm{R} \$ 373,73$ & $\mathrm{R} \$ 98,77$ & $\mathrm{R} \$ 2.925,05$ & $\mathrm{R} \$ 271,80$ & $\mathrm{R} \$ 679,51$ \\
\hline jul/19 & $\mathrm{R} \$ 3.336,79$ & $\mathrm{R} \$ 367,05$ & $\mathrm{R} \$ 90,66$ & $\mathrm{R} \$ 2.879,08$ & $\mathrm{R} \$ 266,94$ & $\mathrm{R} \$ 667,36$ \\
\hline ago/19 & $\mathrm{R} \$ 3.370,13$ & $\mathrm{R} \$ 370,71$ & $\mathrm{R} \$ 95,11$ & $\mathrm{R} \$ 2.904,31$ & $\mathrm{R} \$ 269,61$ & $\mathrm{R} \$ 674,03$ \\
\hline set/19 & $\mathrm{R} \$ 3.613,91$ & $\mathrm{R} \$ 397,53$ & $\mathrm{R} \$ 127,66$ & $\mathrm{R} \$ 3.088,72$ & $\mathrm{R} \$ 289,11$ & $\mathrm{R} \$ 722,78$ \\
\hline out/19 & $\mathrm{R} \$ 3.375,96$ & $\mathrm{R} \$ 371,36$ & $\mathrm{R} \$ 95,89$ & $\mathrm{R} \$ 2.908,71$ & $\mathrm{R} \$ 270,08$ & $\mathrm{R} \$ 675,19$ \\
\hline nov/19 & $\mathrm{R} \$ 3.406,25$ & $\mathrm{R} \$ 374,69$ & $\mathrm{R} \$ 99,93$ & $\mathrm{R} \$ 2.931,63$ & $\mathrm{R} \$ 272,50$ & $\mathrm{R} \$ 681,25$ \\
\hline dez/19 & $\mathrm{R} \$ 3.494,71$ & $\mathrm{R} \$ 384,42$ & $\mathrm{R} \$ 111,74$ & $\mathrm{R} \$ 2.998,55$ & $\mathrm{R} \$ 279,58$ & $\mathrm{R} \$ 698,94$ \\
\hline 130 Sal. & $\mathrm{R} \$ 3.404,04$ & $\mathrm{R} \$ 374,44$ & $\mathrm{R} \$ 99,64$ & $\mathrm{R} \$ 2.929,96$ & $\mathrm{R} \$ 272,32$ & $\mathrm{R} \$ 680,81$ \\
\hline Férias & - & - & - & & - & - \\
\hline Total & $\mathrm{R} \$ 44.252,47$ & $\mathrm{R} \$ 4.867,79$ & $\mathrm{R} \$ 1.295,29$ & $\mathrm{R} \$ 38.089,39$ & $\mathrm{R} \$ 3.540,20$ & $\mathrm{R} \$ 8.850,49$ \\
\hline
\end{tabular}

Fonte: Dados da pesquisa

A Tabela 2 apresenta o salário recebido pelo empregado 2, que atua na função de açougueiro do supermercado. Inicialmente destaca-se que este empregado não teve férias no período analisado, entretanto, estavam marcadas para o mês $02 / 2020$. 
O montante líquido recebido pelo empregado no período foi de $\mathrm{R} \$ 38.089,39$, além disso, o somatório de depósitos na conta do empregado totalizou $\mathrm{R} \$ 3.540,20$ durante o ano de 2019. Assim como ocorre com o empregado 1, o salário bruto do empregado 2 possui variações entre os meses devido a execução de horas extra jornada. Quanto ao INSS, este se enquadrou na alíquota de $11 \%$, entretanto o empregado 2 possui desconto de IRRF em todos os meses, variando entre uma alíquota de 15\% e 22,5\%. Em relação aos custos deste empregado para o empregador, estes foram de $\mathrm{R} \$ 56.643,16$. Isso ocorre, pois além do salário bruto, houve o recolhimento do FGTS e do INSS patronal a alíquotas de $8 \%$ e $20 \%$ respectivamente.

A Tabela 3, tem por objetivo apresentar os cálculos realizados para o empregado 1 com base em um contrato de regime por MEI, onde o prestador de serviço deve possuir CNPJ próprio e emitir notas fiscais para o contratante, sendo o prestador do serviço responsável pelas obrigações tributárias principais e acessórias.

Tabela 3 - Custos Prestador 1 por Contrato MEI

\begin{tabular}{c|c|c|c}
\hline \multicolumn{5}{c}{ Auxiliar de Açougue - Prestador MEI } \\
\hline Mês & Valor NF & Valor MEI & Líquido \\
\hline jan/19 & $\mathrm{R} \$ 1.867,16$ & $\mathrm{R} \$ 54,90$ & $\mathrm{R} \$ 1.812,26$ \\
\hline $\mathrm{fev} / 19$ & $\mathrm{R} \$ 1.842,15$ & $\mathrm{R} \$ 54,90$ & $\mathrm{R} \$ 1.787,25$ \\
\hline $\mathrm{mar} / 19$ & $\mathrm{R} \$ 1.853,53$ & $\mathrm{R} \$ 54,90$ & $\mathrm{R} \$ 1.798,63$ \\
\hline $\mathrm{abr} / 19$ & $\mathrm{R} \$ 1.829,47$ & $\mathrm{R} \$ 54,90$ & $\mathrm{R} \$ 1.774,57$ \\
\hline mai/19 & $\mathrm{R} \$ 1.862,11$ & $\mathrm{R} \$ 54,90$ & $\mathrm{R} \$ 1.807,21$ \\
\hline jun/19 & - & $\mathrm{R} \$ 54,90$ & - \\
\hline jul/19 & $\mathrm{R} \$ 1.935,25$ & $\mathrm{R} \$ 54,90$ & $\mathrm{R} \$ 1.880,35$ \\
\hline ago/19 & $\mathrm{R} \$ 2.142,34$ & $\mathrm{R} \$ 54,90$ & $\mathrm{R} \$ 2.087,44$ \\
\hline set/19 & $\mathrm{R} \$ 1.795,53$ & $\mathrm{R} \$ 54,90$ & $\mathrm{R} \$ 1.740,63$ \\
\hline out/19 & $\mathrm{R} \$ 1.847,75$ & $\mathrm{R} \$ 54,90$ & $\mathrm{R} \$ 1.792,85$ \\
\hline nov $/ 19$ & $\mathrm{R} \$ 1.864,78$ & $\mathrm{R} \$ 54,90$ & $\mathrm{R} \$ 1.809,88$ \\
\hline dez/19 & $\mathrm{R} \$ 1.917,22$ & $\mathrm{R} \$ 54,90$ & $\mathrm{R} \$ 1.862,32$ \\
\hline $13^{\circ}$ Sal. & - & - & - \\
\hline Férias & - & - & $\mathrm{R} \$ 20.098,49$ \\
\hline Total & $\mathrm{R} \$ 20.757,29$ & & \\
\hline
\end{tabular}

Fonte: Dados da pesquisa

Para elaboração da Tabela 3, tomou-se por base o valor da NF com o mesmo valor registrado na carteira de trabalho mediante contrato por CLT. O valor do MEI, trata-se do montante a ser recolhido pelo prestador do serviço 
como formalização junto a previdência social. Para o ano de 2019 esse valor é de $\mathrm{R} \$ 54,90$. Entretanto, percebe-se que quando contratado como prestador de serviço, este profissional perderá as remunerações do $13^{\circ}$ salário, bem como férias. Além disso, caso não efetue a prestação de serviços no mês, o recolhimento da taxa do MEI é obrigatória, como ocorreu no mês de junho. Nesse caso, a grande vantagem para o empregador é que o custo com o prestador é apenas o contido na nota fiscal, não sendo necessário o recolhimento do FGTS e INSS patronal.

A seguir, tem-se a Tabela 4, a qual tem por objetivo discutir o contrato do Açougueiro, caso este fosse contratado para prestar serviços na modalidade MEI.

Tabela 4 - Custos Prestador 2 por Contrato MEI

\begin{tabular}{c|c|c|c}
\hline \multicolumn{5}{c}{ Açougueiro - Prestador MEI } \\
\hline Mês & Valor NF & Valor MEI & Líquido \\
\hline jan/19 & $\mathrm{R} \$ 3.375,96$ & $\mathrm{R} \$ 54,90$ & $\mathrm{R} \$ 3.321,06$ \\
\hline $\mathrm{fev} / 19$ & $\mathrm{R} \$ 3.362,50$ & $\mathrm{R} \$ 54,90$ & $\mathrm{R} \$ 3.307,60$ \\
\hline $\mathrm{mar} / 19$ & $\mathrm{R} \$ 3.339,79$ & $\mathrm{R} \$ 54,90$ & $\mathrm{R} \$ 3.284,89$ \\
\hline $\mathrm{abr} / 19$ & $\mathrm{R} \$ 3.380,00$ & $\mathrm{R} \$ 54,90$ & $\mathrm{R} \$ 3.325,10$ \\
\hline $\mathrm{mai} / 19$ & $\mathrm{R} \$ 3.394,88$ & $\mathrm{R} \$ 54,90$ & $\mathrm{R} \$ 3.339,98$ \\
\hline jun/19 & $\mathrm{R} \$ 3.397,55$ & $\mathrm{R} \$ 54,90$ & $\mathrm{R} \$ 3.342,65$ \\
\hline jul/19 & $\mathrm{R} \$ 3.336,79$ & $\mathrm{R} \$ 54,90$ & $\mathrm{R} \$ 3.281,89$ \\
\hline ago/19 & $\mathrm{R} \$ 3.370,13$ & $\mathrm{R} \$ 54,90$ & $\mathrm{R} \$ 3.315,23$ \\
\hline set/19 & $\mathrm{R} \$ 3.613,91$ & $\mathrm{R} \$ 54,90$ & $\mathrm{R} \$ 3.559,01$ \\
\hline out/19 & $\mathrm{R} \$ 3.375,96$ & $\mathrm{R} \$ 54,90$ & $\mathrm{R} \$ 3.321,06$ \\
\hline nov $/ 19$ & $\mathrm{R} \$ 3.406,25$ & $\mathrm{R} \$ 54,90$ & $\mathrm{R} \$ 3.351,35$ \\
\hline dez/19 & $\mathrm{R} \$ 3.494,71$ & $\mathrm{R} \$ 54,90$ & $\mathrm{R} \$ 3.439,81$ \\
\hline $13^{\circ}$ Sal. & - & - & - \\
\hline Férias & - & - & $\mathrm{R} \$ 40.189,63$ \\
\hline Total & $\mathrm{R} \$ 40.848,43$ & & \\
\hline
\end{tabular}

Fonte: Dados da pesquisa

A Tabela 4 apresenta os custos com o prestador de serviço da função açougueiro. É importante destacar que o MEI pode ter um faturamento anual de $\mathrm{R} \$ 81.000,00$ por ano, o que representa uma média de $\mathrm{R} \$ 6.750,00$ por mês, que independentemente do faturamento, o valor de recolhimento para o MEI continuará $\mathrm{R} \$ 54,90$. Para o empregador, o custo será fixo de $\mathrm{R} \$ 40.848,43$, pois não ocorre o recolhimento de INSS patronal, nem de FGTS. 
A seguir, a Tabela 5 apresentará um comparativo sintético, sob as duas óticas: Empregado e Empregador, ou então Prestador e Tomador. O objetivo desta tabela é responder o objetivo da pesquisa que consiste em de avaliar as vantagens e desvantagens da terceirização da mão de obra, sob a ótica do empregado e empregador levando em consideração os aspectos econômicos, legais e sociais envolvidos na relação trabalhista de duas maneiras de contrato de trabalho, via Consolidação das Leis Trabalhistas (CLT) e via contrato de terceirização por Micro Empreendedor Individual (MEI).

Tabela 5 - Comparativo da Terceirização Versus CLT

\begin{tabular}{cc|cc|cc|cc}
\hline \multicolumn{7}{c|}{ Remuneração Líquida sob a Ótica do Empregado/Prestador de Serviço } \\
\hline \multicolumn{2}{c|}{ CLT 1 } & \multicolumn{2}{c|}{ MEI 1 } & \multicolumn{2}{c}{ CLT 2 } & \multicolumn{2}{c}{ MEI 2 } \\
\hline Líquido & FGTS & Valor NF & Líquido & Líquido & FGTS & Valor NF & Líquido \\
$\mathrm{R} \$ 22.791,78$ & $\mathrm{R} \$ 2.005,68$ & $\mathrm{R} \$ 20.757,29$ & $\mathrm{R} \$ 20.098,49$ & $\mathrm{R} \$ 38.089,39$ & $\mathrm{R} \$ 3.540,20$ & $\mathrm{R} \$ 40.848,43$ & $\mathrm{R} \$ 40.189,63$ \\
\hline $\begin{array}{c}\text { Líquido } \\
\text { CLT }\end{array}$ & $\mathrm{R} \$ 24.797,46$ & $\begin{array}{c}\text { Líquido } \\
\text { MEI }\end{array}$ & $\mathrm{R} \$ 20.098,49$ & $\begin{array}{c}\text { Líquido } \\
\text { CLT }\end{array}$ & $\mathrm{R} \$ 41.629,58$ & $\begin{array}{c}\text { Líquido } \\
\text { MEI }\end{array}$ & $\mathrm{R} \$ 40.189,63$ \\
\hline
\end{tabular}

\begin{tabular}{ccc|c|ccc|c}
\hline \multicolumn{7}{c}{ Custos da Mão de Obra sob a Ótica do Empregador/Contratante do Serviço } \\
\hline CLT 1 & & MEI 1 & & CLT 2 & MEI 2 \\
\hline Sal. Bruto & FGTS & INSS Pat. & Valor NF & Sal. Bruto & FGTS & INSS Pat. & Valor NF \\
R $\$ 25.070,99$ & $\mathrm{R} \$ 2.005,68$ & $\mathrm{R} \$ 5.014,20$ & $\mathrm{R} \$ 20.757,29$ & $\mathrm{R} \$ 44.252,47$ & $\mathrm{R} \$ 3.540,20$ & $\mathrm{R} \$ 8.850,49$ & $\mathrm{R} \$ 40.848,43$ \\
\hline Custo CLT & $\mathrm{R} \$ 32.090,87$ & Custo MEI & $\mathrm{R} \$ 20.757,29$ & Custo CLT & $\mathrm{R} \$ 56.643,16$ & Custo MEI & $\mathrm{R} \$ 40.848,43$ \\
\hline
\end{tabular}

Fonte: Dados da pesquisa

Os dados apresentados na Tabela 5 revelam que para os dois funcionários a opção pela terceirização não é vantajosa. Embora, o Empregado/Prestador de serviço 2 receba um montante maior pelo contrato do MEI em relação ao líquido da CLT, o empregado deve levar em consideração os depósitos que são realizados em sua conta no FGTS, que correspondem a $8 \%$ da sua remuneração bruta.

Ao analisar os dois cenários: Terceirização versus CLT sob a ótica do empregador, a terceirização torna-se extremamente vantajosa. No caso do Empregado/Contratado 1, é possível observar uma redução de 35,32\% nos custos de mão de obra, enquanto que o Empregado/Contratado 2 responde por uma redução de $27,88 \%$ nos custos com mão de obra.

Ao finalizar os cálculos da simulação do regime de contratação pelo MEI, os cálculos foram apresentados aos empregados para que avaliassem a possibilidade desse tipo de contrato. $\mathrm{O}$ objetivo era identificar a percepção destes em relação a uma nova modalidade de trabalho, onde passariam a ser prestadores de serviços e não empregados mais empregados sob contrato CLT. O empregado 1 percebeu que não é nada vantajoso no seu caso pois receberia 
quase $\mathrm{R} \$ 5.000,00$ a menos via terceirização. Essa diferença se dá pelo motivo do não recebimento de férias, $13^{\circ}$ e FGTS. Já o empregado 2 teria uma diferença um pouco menor em relação ao empregado 1. Este receberia cerca de $\mathrm{R} \$ 1.500,00 \mathrm{a}$ menos pelo contrato de terceirização, entretanto, o Empregado 2 demonstrou bastante interesse nessa modalidade de contrato, pois na sua percepção, seria possível negociar um montante maior por mês com o tomador do serviço, visto que este economizaria um valor considerável com a terceirização. Na visão do empregador, este demonstrou bastante interesse em adotar o processo de terceirização. Nesse sentido, o único entrave seria a questão do prazo para contratação do mesmo empregado como terceirizado, que deveria respeitar o prazo de 18 meses conforme determina a legislação.

\section{CONCLUSÃO}

Ao analisar a questão em um panorama geral, nota-se que é possível, e viável a troca da contratação celetista pela contratação terceirizada, seja por MEI ou empresa especializada, em que pese diminui os encargos financeiros para a empresa, com a diminuição na folha de pagamento com os valores de férias, $13^{\circ}$ salário, CPP e FGTS. Bem como gera eficiência e qualidade no serviço. Para os empregados a vantagem surge do aumento do salário mensal, mas em contra ponto alguns direitos celetistas não se transmitem ao terceirizado, ou não são suportados pela empresa tomadora, mas pela empresa terceirizada.

Ao se apresentar a possibilidade e os dados obtidos pela pesquisa ao gestor da empresa, este demonstrou interesse na terceirização, porém, constatou-se que o mesmo gostaria de manter a atual equipe, pela sua confiabilidade, eficiência e ética de trabalho, todavia tal perspectiva é vedada pela lei, que considera fraude a contratação por terceirização de ex-funcionário com prazo inferior a 18 meses, a contar da data da demissão.

Vale destacar que existem outros custos diretamente relacionados aos empregados, quando contratados por meio de CLT que são difíceis de mensurar. Entretanto é sabido que ocorrem e devem ser lembrados pela empresa, tais como: exames admissionais, periódicos, demissionais, gastos com equipamentos de proteção individual, entre outros tantos que no MEI são inexistentes. Além disso, o empregado tem proteção da CLT em diversos casos em que a falta é justificada, como atestados médicos, licenças de gala, etc... Enfim, várias faltas em que ele é remunerado.

Assim sendo, pose-se concluir que há mais vantagens para o tomador de serviço terceirizado do que desvantagens, apesar disso a hipótese levantada por este trabalho não pode ser aplicada no caso de estudo por não se adaptar a realidade vivida pela empresa, que atua com o mesmo funcionário a mais de 10 anos e demostrou interesse em manter o mesmo funcionário na dinâmica da terceirização, o que não pode ocorrer por força de lei. Deste modo, conclui-se 
pela viabilidade da aplicação da terceirização desde que levada em conta as limitações legais e a aplicabilidade a realidade do caso concreto.

Em relação ao empregado, é possível afirmar que não existem muitas vantagens de um contrato de terceirização, no caso de receber por seus serviços o mesmo valor que receberia num contrato CLT. Entretanto, este poderá negociar um valor maior para remunerar seus serviços prestados, o que deve ser levado em conta pelo contratante dos serviços, afinal este obtém uma diminuição significativa de custos quando comparada a terceirização com a contratação celetista.

Ademais, cabe ressaltar que o processo de terceirização pode criar um impacto social muito grande se levar em conta o recolhimento da previdência. Afinal, o empregador deixa de recolher $20 \%$ de INSS patronal, e o contratado por MEI deixa de recolher $8 \%, 9 \%$ ou $11 \%$ do seu salário para a previdência social, nesse sentido recolherá apenas a taxa do MEI, que atualmente é de $\mathrm{R} \$ 54,90$. Sendo assim, é necessário um equilíbrio por parte dos órgãos reguladores a fim de diminuir os impactos deste processo.

\section{REFERENCIAS}

ALTIN, Mehmet; UYSAL, Muzaffer; SCHWARTZ, Zvi. Revenue management outsourcing: a hybrid model of transaction cost economics and organizational capability. Cornell Hospitality Quarterly, v. 59, n. 2, p. 112-124, 2018.

BAYTOK, AHMET; HASAN, HUSEYIN SOYBALI; ZORLU, Ozcan. Outsourcing in thermal hotel enterprises: The case of Turkey. Business Management Dynamics, v. 3, n. 5, p. 1, 2013.

BRASIL, Senado Federal. Constituição federal de 1988. Fonte: Planalto. gov. br: http:// www. planalto. gov. br/ccivil_03/constituicao/constituicaocompilado. htm, 1988.

CASTRO, Rubens Ferreira de. A terceirização no direito do trabalho. São Paulo: Malheiros, 2018.

CHATZOGLOU, Prodromos D.; SARIGIANNIDIS, Lazaros. Business outsourcing and organisational performance: The case of the Greek hotel industry. International Journal of Services Technology and Management, v. 11, n. 2, p. 105-127, 2009.

DELGADO, Gabriela Neves. Terceirização: paradoxo do direito trabalho contemporâneo. São Paulo: LTr, 2004.

ELMUTI, Dean. The perceived impact of outsourcing on organizational performance. American Journal of business, 2003.

ESPINO-RODRÍGUEZ, Tomás F.; GIL-PADILLA, Antonia M. The impact of outsourcing strategies on information systems capabilities in the hotel industry. The Service Industries Journal, v. 27, n. 6, p. 757-777, 2007. 
ESPINO-RODRÍGUEZ, Tomás F.; LAI, Pei Chun; BAUM, Tom. Risks and benefits of outsourcing hotel operations: A comparison between Scotland and Taiwan. Tourism Economics, v. 18, n. 1, p. 95-120, 2012.

ESPINO-RODRÍGUEZ, Tomás F.; RAMÍREZ-FIERRO, Juan Carlos. Managers' attitudes toward hotel outsourcing in a tourist destination. An approach from the benefits and risks perspective. Tourism management perspectives, v. 26, p. 143-152, 2018 .

FREDIANI, Yone. Direito do Trabalho. Barueri, Sp: Manole, 2011.

GABAS Renato Hiro Y. A flexibilização das condições trabalhistas decorrente dos efeitos da globalização e crises econômicas. 2016. Disponível em < https: / /jus.com. $\mathrm{br} /$ artigos/51610/a-flexibilizacao-das-condicoes-trabalhistas decorrente-dos-efeitosda-globalizacao-e-crises-economicas >

GILLEY, K. Matthew; GREER, Charles R.; RASHEED, Abdul A. Human resource outsourcing and organizational performance in manufacturing firms. Journal of business research, v. 57, n. 3, p. 232-240, 2004.

NASCIMENTO, Amauri Mascaro; NASCIMENTO, Sônia Mascaro. Curso de direito do trabalho: história e teoria geral do direito do trabalho: relações individuais e coletivas do trabalho. 29 ed. São Paulo: Saraiva, 2014.

PONTES, R. N. Proposta de implementação de um planejamento estratégico para uma empresa de pequeno porte (epp), do ramo de confecção inserida no mercado atacadista da região sul de Santa Catarina. Monografia (Conclusão de Curso Ciências Contábeis) - Universidade do Extremo Sul Catarinense. Criciúma, Santa Catarina, 2011.

SERAU JUNIOR, Marco Aurélio, et. al. Terceirização: conceitos, críticas, reflexos trabalhistas e previdenciários. São Paulo: LTr, 2018.

SOARES JUNIOR, Alcídio. A terceirização e o enfoque de seus conceitos. Revista Jus Navigandi, ISSN 1518-4862, Teresina, 2013.

SOUZA, André Portela et al. Custo do Trabalho no Brasil: Proposta de uma nova metodologia de mensuração. FGV/EESP, 2012.

VIDAL NETO, Pedro. A terceirização perante o direito do trabalho. São Paulo: LTr, 1996. 